\title{
Research on the Training Mode of Teacher Educational Practice Ability of Normal College Students Based on the Perspective of Integration*
}

\author{
Shuai Yang \\ Chuxiong Normal University \\ Chuxiong, China
}

\author{
Haicheng Bai \\ Yunnan Normal University \\ Kunming, China
}

\begin{abstract}
With the reform of education, especially the reform of basic education, the development of basic education is in urgent need of teachers with integrated views. Thus, the traditional teacher education model in normal colleges and universities should be changed accordingly. Innovation is the key in such reform. With this as basis, the "integrated" teacher education practice teaching mode of the normal colleges and universities consisting of coherent basic education and organic fusion of all subjects is proposed.
\end{abstract} model

Keywords-integration; teacher education; practical ability;

\section{INTRODUCTION}

Education is the foundation of social development. The key to education development lies in teachers. It is the urgent task and goal of the current teacher education to cultivate a large number of outstanding teachers who can meet the needs of current education development and to continuously improve the overall quality of the teaching staff. The teacher education curriculum standard is China's basic requirement for the establishment of teacher education curriculum for educational institutions. It is an important basis for formulating teacher education curriculum programs, developing teaching materials and curriculum resources, conducting teaching and evaluation, and identifying teacher qualifications. "The Teacher Education Curriculum Standards (Trial)" issued by the Ministry of Education in 2011 pointed out that the teacher education curriculum broadly includes the public foundation courses, subject professional courses and education courses provided by the teacher education institutions for cultivating and training kindergarten, primary and secondary school teachers. This paper studies the cultivation of educational practice ability in educational courses. 2017 witnessed the issuance of "Opinions on Promoting the Reform of Teacher Education Curriculum by Ministry of Education", which stipulated the provisions and requirements for the structure of teacher education curriculum, the teaching content of teacher education curriculum, and the educational practice. The

*Fund: This paper is supported by Digital Campus Information System Development Research Project of Chuxiong Normal University: Design and Development of Teacher Education Technology Training Website in Digital Campus Environment. Project No. SZZX1402.
"Opinions" pointed out that it's important to "optimize the structure of teacher education curriculum", "scientifically set public basic courses, professional courses and teacher education courses for normal school students" and "guarantee the needs of new teachers to adapt to the new basic education curriculum."

The cultivation of teachers' educational practice ability is a process for normal school students to understand the reality of education, experience education practice, accumulate educational skills, master educational theory, and generate educational concepts. It is of great significance to the students majoring in teachers in normal colleges and universities. It should be emphasized that the teacher education practice refers to a series of practice-oriented activities that are closely related to theoretical teaching, through which students can gain direct perceptual cognition, basic skills, and improve their overall quality of education under the guidance of teachers. Teacher is a practical application-oriented occupation, which means that the future teachers, current normal college students need to undergo "clinical" internships to take up the future professional tasks. This "clinical" mainly relies on teacher education practice. At present, the basic education promote the integration of the phases of studying and the integration of disciplines, only "integrated" teachers can be well qualified for the education work. What's more, after the connotation of normal college students education is expanded into teacher education and undergoing professionalization, practice teaching has become an approach equal to theoretical teaching for the cultivation of teachers in teacher education. As an important way to improve the educational practice ability of normal college students, the reform of the teaching practice of normal school students has naturally become the key to the reform of teacher education today.

According to data from the Organization for Economic Co-operation and Development (OECD), teacher education models in many countries have turned to practice, shifted from academic training to practice-oriented professional training in school to seek a balance and harmony between theory and practice [1]. For example, the PSD (Professional Development School) model in US [2] is a long-term partnership between universities and basic schools, which can promote the professional development of teachers, and 
emphasizes educational field experience of normal college students before they graduate. Singapore has identified "the fundamental path for development of normal college students based on practice" and has attached great importance on educational practice. It has established a community model of "three-way cooperation" based on the three-party cooperation model of the Ministry of Education, the College of Education, and the primary and secondary schools, and an educational practice management institution [3]. What's more, Russia and France [4] have also changed their teaching model of education practice. All mentioned above have fully revealed the importance of the improvement of the practical ability of normal college students in teacher education. It can be seen that strengthening and reforming the teacher practice education has become an inevitable trend in the development of teacher education in all countries of the world.

\section{THE SIGNIFICANCE OF INNOVATING THE TEACHERS' EduCATIONAL PRACTICE ABILITY OF NORMAL COLLEGE STUDENTS}

Innovation-driven development has become a major trend in social development. Given the new situation and new requirements of social development, it's important to consider the situation, thoroughly analyze the current needs of the society for education development, and current problems of teacher education, based on which to realize the new trend of innovation-oriented education and solve newly emerging problems in education.

It's a must to take innovation as the first driving force for the development of teacher education practice teaching, reform the mode of teacher education practice teaching that contradicts the development concept of new era education to promote the innovation and development of the whole education.

The innovation of the teacher education practice model aiming at cultivating the practical ability of normal college students should be based on the current education reform, and should meet the requirements of the current educational reform and development on the educational practice ability of normal college students. At present, China has comprehensively deepened its education reform, paid more attention to comprehensive education and education in the whole process, focused on strengthening the vertical cohesion and horizontal cooperation of disciplines, and taken the interdisciplinary all-round and comprehensive education as an important task. Wholeness and synthesis is a new trend in education reform. The so-called whole is to break the original model of school-segment education, to connect the various sections to carry out the overall design, and strengthen the close relationship between the sections; while the integration refers to the integration of disciplines and disciplines. The previous teaching frameworks are mostly dominated by sub-discipline teaching, but in reality, it is impossible to use any single discipline to understand the world and solve real-world problems. Therefore, education reform should regard the construction of a comprehensive curriculum framework and integration of interdisciplinary and inter-semester courses. Therefore, the normal colleges and universities should also take the cultivation of students with integrated thinking and skills as their main task when conducting teacher education practice teaching for normal school students. Based on this, this paper proposes to innovate the training mode of teachers' educational practice ability of normal college students from the perspective of integration.

\section{CONSTRUCTION OF THE TRAINING MODE OF INTEGRATED TEACHERS' EDUCATIONAL PRACTICE ABILITY OF NORMAL COLLEGES STUDENTS}

\section{A. The Theoretical Basis of the Training Mode of Inter- semester Integrated Normal School Students' Educational Practice Ability}

For a long time, China has generally implemented a graded teacher education system in teacher education, that is, the training of normal school students is specifically targeted at a specific studying phase. The training of primary school teachers, junior high school teachers, and high school teachers is often carried out relatively independently, but at present, with the development of the times, higher requirements have been placed on education, and basic education reform has been deepened. The education reform attaches great importance to the law of physical and mental development of primary and middle school students, emphasizes the characteristics of coherence, system, predecessor, convergence and increment of knowledge learning among primary and secondary school students, and establishes a consistent nine-year class category and class ratio, resolving the issue of relative splitting, closure, and repeated crossovers of curriculum of each primary and secondary school. At the same time, the problem of graded training for students in normal colleges and universities is also becoming more and more prominent as it contradicts the actual needs of the society. In order to solve the problem, it's needed to keenly capture the needs to reform basic education and teacher education, transform the traditional teacher training model, provide an integrated and coherent teacher education model for normal school students, and provide opportunities to learn basic education of all stages. Chinese scholars have also carried out a large number of related researches. For example, Luo Mingdong and other scholars have put forward that "integration, comprehensiveness and unified training of the cultivation of primary school teachers, junior high school teachers and high school teachers; such cultivation should cover all stages of basic education, while highlighting certain stage in basic education, rather than the traditional teacher education model that only focuses on a certain stage of basic education." [5]

The existing research is mainly carried out from the macro level of teacher education. How to develop the practical ability of normal school students in teacher education? The practical teaching aiming at cultivating the practical ability of normal school students is an important part of teacher education, which has an irreplaceable role in improving the comprehensive quality of normal school students and cultivating their innovative spirit. Strengthening 
practical teaching is an important focus for improving the practical ability of normal school students.

The cross-semester training mode for improving the education practice ability of normal school students pays attention to the coherence and integrity of basic education, emphasizing the "whole + phase", that is, on the basis of paying attention to the basic education as a whole, pay attention to its stages, so as to cultivate new faculty talents who understand the teaching principles and methods of basic education, have a holistic view, deeply grasp the teaching theory and practice of a certain stage of basic education, and finally can undertake the teaching of various stages of basic education.

\section{B. Cross-semester Training Mode for Improving}

Educational Practice Ability of Integrated Normal School Students: a Training Mode that Realizes "Virtual and Real Combination, Internal and External Integration"

The virtual and real combination is the combination of virtual environment and real environment. The virtual environment is the training room in colleges and universities that can simulate all stages in basic education, which provides the normal school students with practical training scenes close to the real working environment of each section of the basic education. Students can use the virtual training room to simulate job development and develop professional skills. At present, technologies such as VR, multimedia, artificial intelligence and network communication are developing rapidly, which provides a strong technical guarantee for the construction of high-simulation training rooms, through which students can carry out teaching design, teaching activities in such intuitive and vivid virtual scene, as well as integration of data collection and analysis, interactive communication, evaluation and other functions. Therefore, higher normal colleges should actively carry out the development and application of relevant resource platforms, and actively apply existing advanced information technology to the cultivation of practical skills of normal school students to meet the growing needs of students to be integrated talents. The real environment is a real-life situation in the school. With the various software and hardware resources provided by the school, theory and practice can be effectively combined to improve professional ability. Through the combination of virtual and real, each other's strengths can be complemented to jointly promote the ability of normal school students. Given the fact that the cross-semester training of integrated normal school students covers the primary, middle and high school sections, there exist challenges such as long time, difficult management, and difficult organization in specific practical teaching, especially in educational internships, the mainly used practical method. The combination of virtual and real can effectively solve such problems. In particular, the construction of virtual training space based on the network platform can break the time and space restrictions and share cross-semester education practice activities widely.

Internal and external refers to the inside and outside of higher normal colleges and universities, which is an important force for cultivating teacher talents. With the increasing demands of the society for quality normal school students, colleges and universities should actively explore external resources, make full use of both internal and external resources, and improve the integration ability of normal school students to better serve basic education. External resources mainly refer to primary and secondary schools, various administrative departments of education, educational research departments, and educational resource development enterprises. It's possible to strengthen internal and external integration to achieve the mechanism of "coeducation, co-management, co-construction and sharing".

"Co-education" refers to the base training activities and training bases construction launched by higher normal colleges and schools of basic education. It is helpful to provide practical places for normal school students, jointly cultivate talents in accordance with the personnel training program in a phased and hierarchical manner, and lay a good foundation for students to master educational practice skills and land job smoothly. At the same time, higher normal colleges and universities impart advanced education concepts and technologies to help teachers in basic education schools, and achieve the goal of win-win and common education.

"Co-management" is mainly reflected in the smooth link of the education policy. Higher normal colleges are supposed to be closely linked with the education administrative departments and educational research departments to seek guidelines and help for reform and development. At the same time, the higher normal colleges will feedback the results of the reform to the above-mentioned departments, and provide demonstrations to further deepen and expand the application of the results.

"Co-construction" refers to the cooperation between higher normal colleges and educational resource development enterprises to build modern educational resources, such as the virtual training platform mentioned above.

The purpose of "sharing" is to effectively achieve a winwin outcome within and outside the higher normal colleges. It's needed to focus on the cultivation of integrated normal school students talents based on reform, highlight the construction of models, improve the quality of social services, share talent training results and information resources, and achieve multilateral win-win outcome and mutual benefit to effectively solve problems in the traditional practice teaching system, jointly improve the "integration quality" of normal school students, and promote basic education faster and better.

\section{Interdisciplinary Training Mode for Improving Educational Practice Ability of Integrated Normal School Students: Open Project-driven Mode}

The "Basic Education Curriculum Reform Outline (Trial)" formulated by the Ministry of Education clearly states that "it's indispensable to change the subject-based curriculum structure with too many subjects and lack integration." It can be seen that the comprehensive principle 
is a major breakthrough in the reform of basic education. At the same time, new requirements are put forward for teachers' comprehensive quality, especially for integration ability. Therefore, higher normal colleges should focus on the cultivation of the integrated teaching ability of normal school students. Only by actively reforming the single educational practice model can the normal schools cultivate future teachers with comprehensive ability that can meet the needs of basic education reform.

Based on the interdisciplinary integration ability training, an open project-driven education practice ability training model for normal school students is proposed. This model uses the project as the carrier to create a multi-education practice project platform for normal school students. As regards to top-level design, higher normal colleges carried out the development of in-depth and extensive cross-subject curriculum of each major, and integrate them into projects to demonstrate the knowledge of various subjects of basic education in the form of projects. The project-based curriculum should be based on real-world problems, break the chapter restrictions, reconstruct the existing curriculum content, and integrate the original isolated and scattered knowledge points into one project. The project is derived from the real problems in real life, through the appropriate situational creation, and it can promote students' internalization and migration of curriculum knowledge in the practical application. [6]

The open project-driven practice ability training model for normal school students requires breaking the limitations of the original closed and structured teacher education practice teaching, and taking the project-style comprehensive practice as the main form to provide students with more flexible and diversified educational practice environment. It allows students to choose different projects and ways in accordance with their own interests and needs to achieve integrated development in their own or collaborative processes. The specific development method is as follows: firstly, it is guided by professional teachers to integrate the subject teaching resources into multiple projects. When the normal school students are engaged in the subject teaching practice activities, they need to select projects across modules, which include information technology, art, music, literature, sports, psychology, etc. The grid-based project teaching practice activities provide rich development possibilities for normal school students, and effectively enhance students' interdisciplinary integration teaching ability.

\section{CONCLUSION}

The primary task of current education is to cultivate innovative talents. Therefore, the goal in the field of teacher education in normal colleges and universities is to train normal school students who are qualified to this task. The practice of the integrated education practice ability training mode for normal school students takes the perspective of comprehensive development values, the development concept of modern comprehensive concept, the talent view of general education, and the curriculum view of knowledge integration, which provide the higher education institutions with educational concepts to cultivate teachers with integrated qualities. This paper focuses on the discussion of relevant model theory. The follow-up research will pay more attention to concrete practice, strengthen the combination of theory and practice, and jointly promote the improvement of the integrated practical ability of normal school students.

\section{REFERENCES}

[1] OECD. Building a High-quality Teaching Profession Lessons from Around The World [R]. 2011: 2.

[2] Xiang Kehong. Research on PDS Model of Pre-service Practice of Teacher Education in American [D]. Chongqing Normal University, 2016. (in Chinese)

[3] Lu Daokun, Ding Chunyun. Teacher Education Model of National Institute of Education, Nanyang Technological University, Singapore [J]. Higher Education Exploration, 2018(09). (in Chinese)

[4] Wu Jing. Analysis on the Reform of Teacher Education Practice Teaching in Local Normal Colleges and Universities [J]. Forward Position. 2012(20). (in Chinese)

[5] Luo Mingdong. Analysis of the Basic Characteristics of the "Integrated and Coherent" Normal Students Training Model [J] Journal of Kunming University [J]. 2011(1). (in Chinese)

[6] Zhang Wenlan, Zhang Siqi, Lin Junfen, Wu Qiong, Chen Shulan Project-based Learning Design and Practice Based on the Concept of Curriculum Reconstruction Against the Network Environment [J]. eEducation Research, 2016(2). (in Chinese) 